\title{
ALTERAÇÃO DE ATRIBUTOS QUÍMICOS DO SOLO E ESTADO NUTRICIONAL E CARACTERÍSTICAS AGRONÔMICAS DE PLANTAS DE MILHO, CONSIDERANDO AS MODALIDADES DE CALAGEM EM PLANTIO DIRETO ${ }^{(1)}$
}

\author{
F. R. PIRES ${ }^{(2)}$, C. M. SOUZA(3), D. M. QUEIROZ(4), \\ G. V. MIRANDA ${ }^{(3)} \& J$, C. C. GALVÃO(3)
}

\begin{abstract}
RESUMO
A aplicação de calcário na superfície do solo em sistema plantio direto, sem incorporação, em determinadas condições edafoclimáticas, não tem sido eficaz na correção da acidez e no fornecimento de cálcio e magnésio às plantas. $\mathrm{Na}$ busca de alternativas para a realização da calagem sem as operações convencionais de aração e gradagem, o trabalho teve como objetivo avaliar a eficiência de diferentes modalidades de calagem nos atri butos quími cos do solo, no estado nutricional e nas características agronômicas da cultura do mi lho. 0 delineamento experimental utilizado foi o de blocos ao acaso, em parcelas subdivididas, com três repetições. Os tratamentos aplicados nas parcelas foram: mi lho híbrido duplo Z 8447, variedade de milho AL 25 e híbrido duplo AG 122 e, nas subparcelas, testemunha sem calagem, calcário aplicado ao longo do perfil do solo no sulco de semeadura, calcário aplicado a lanço na superfície do solo e calcário aplicado ao longo do perfil do solo no sulco de semeadura, mais calcário aplicado a lanço na superfície. Nos tratamentos que receberam calcário no sulco, a semeadura foi realizada no mesmo sulco que recebeu o calcário. A amostragem do solo foi feita 30 e 150 dias após a calagem, a partir da linha de semeadura até $25 \mathrm{~cm}$ de distância desta, em cinco profundidades. Determinaram-se pH em água e Ca, Mg e Al trocáveis nas amostras. Avaliou-se o estado nutricional do tecido foliar dos três cultivares, bem como algumas características agronômicas da cultura. Os resultados indicaram que o calcário aplicado no sulco de semadura foi distribuído eficientemente ao longo do perfil do solo até $20 \mathrm{~cm}$ de profundidade, em uma faixa de $10 \mathrm{~cm}$ de largura. O calcário aplicado na superfície teve efeito sobre as características químicas do solo somente até $5 \mathrm{~cm}$
\end{abstract}

(1) Parte da Tese de Mestrado do primeiro autor. Recebido para publicação em fevereiro de 2002 e aprovado em outubro de 2002.

(2) Doutorando do Curso de Fitotecnia, Universidade Federal de Viçosa - UFV. Av. PH Holfs s/n, CEP 36571-000 Viçosa (MG). E-mail: frpires@alunos.ufv.br

(3) Professor do Departamento de Fitotecnia, UFV.

(4) Professor do Departamento Engenharia Agrícola, UFV. 


\begin{abstract}
de profundidade. A aplicação conjunta de calcário ao longo do perfil do solo no sulco de semeadura mais calcário em superfície foi mais eficiente para elevar os valores de pH e os teores Ca e Mg trocáveis e diminuir os teores de Al trocável. O estado nutricional dos cultivares e as características agronômicas do milho não foram afetados pelos tratamentos.
\end{abstract}

Termos de indexação: calcário, pH, alumínio, cálcio, magnésio, Zea mays L.

SUMMARY: CHANGES IN CHEMICAL SOIL CHARACTERISTICS, NUTRITIONAL STATE, AND AGRONOMIC CHARACTERISTICS OF CORN PLANTS DUE TO LIME APPLICATION FORMS UNDER NO-TILLAGE

\begin{abstract}
Lime application on the soil surface in no-tillage systems, without incorporation, has not been effective in certain edaphic and dimatic conditions for the correction of acidity or for calcium and magnesium supply to plants. Searching alternatives for limestone application without the conventional tilling and harrowing operations, this study tried to evaluate the efficiency of different lime application forms for the chemical soil attributes, nutritional state, and agronomic characteristics of corn crop. A randomized block design with split-plots and threereplications was used. Thetreatments applied on the plots were: double hybrid corn Z 8447; corn variety AL 25; and double hybrid AG 122; and on the split-pl ots: control without liming; limeapplied along thesoil profilein theplanting furrow; limeappli ed by spreading on soil surface; limeappl ied al ong thesoi I profil einto thepl anting furrow plus morelime spread on the soil surface. Wherelime was applied in thefurrows, maizewas sown in thefurrows that had received li me. Soils weresampled 30 and 150 days after liming, from the sowing line to a distance of $25 \mathrm{~cm}$ from the sowing line, and at five depths. The $\mathrm{pH}$ was determined in the water and exchangeable $\mathrm{Ca}, \mathrm{Mg}$ and $\mathrm{Al}$ in the samples. Thenutritional state of foliar tissue was eval uated for the threecultivars, as well as some agronomic crop characteristics. Results showed that the lime applied into the planting furrow was distributed efficiently al ong the soil profile down to a depth of $20 \mathrm{~cm}$, in a $10 \mathrm{~cm}$ wide strip. Surface lime application only had an effect on the chemical soil characteristics down to a depth of $5 \mathrm{~cm}$. The concurrent application along the soil profile into the planting furrow plus morelime on the surface was the most efficient, with higher val ues of $\mathrm{pH}$, exchangeable $\mathrm{Ca}$ and $\mathrm{Mg}$, and lower levels of exchangeableAl. No effect of the lime application mode was observed on the nutritional state of the tested cultivars or the agronomic characteristics of the corn crop.
\end{abstract}

Index terms: lime, pH, alumi num, calcium, magnesium, Zea mays L.

\section{INTRODUÇÃO}

Com a difusão de sistemas conservacionistas de manejo do sol o (cultivo mínimo e plantio direto(PD)), as práticas agronômicas vêm sendo adaptadas, visando à manutenção da capacidade produtiva dos sistemas agrícolas. Dentre essas práticas, destacase a calagem.

Tradicionalmente, o calcário é incorporado até $20 \mathrm{~cm}$ de profundidade, a fim de corrigir a acidez do sol o na camada arável. Contudo, a ação de incorporar o calcário contraria o princípio de movimentação mínima de solo preconizado pelos sistemas conservacionistas de manejo. Por outrolado, a nãoincorporação reduz a superfície de contato entre as partículas do corretivo e os colóides do solo e, em conseqüência, a eficácia da operação (Sá, 1995).
A aplicação superficial decal cário, sem incorporálo, tem sido o procedimento mais comumente utilizado por agricultores para corrigir a acidez do solo em condições de cultivo mínimo e, principalmente, em PD. Essa prática contribui para corrigir a acidez apenas na camada superficial $(5 \mathrm{~cm})$, em virtude da baixa mobilidade e solubilidade apresentada pelo calcário. Por esse motivo, ocorre maior concentração deraízes na camada superficial, expondo as plantas a déficits hídricos (Bayer \& Mielniczuk, 1997; Pöttker \& Ben, 1998). Em condições de déficit hídrico, o não-aprofundamento do sistema radicular dificulta a utilização de água armazenada no subsolo, prejudicando o desenvolvimento e a produção das culturas (Silva et al., 1984ab).

A aplicação superficial de cal cário mantém o pH e os teores de $\mathrm{Al}^{3+}$ em níveis não-limitantes ao 
desenvolvimento das plantas (Santos et al., 1995). Essa situação tem sido observada na maioria dos trabalhos realizados, nos quais, apesar de o efeito da calagem restringir-se às camadas superficiais (Ernani et al., 1998), a produção das diversas culturas não tem sido afetada. Isso leva a crer que, mesmo com uma pequena camada corrigida do perfil, as plantas conseguem desenvolver-se e produzir normalmente (Scott et al., 1997; Rodrigues, 1997). A restrição ao aprofundamento do sistema radicular pode ser rel evante, em condições de déficits hídricos (Pöttker \& Ben, 1998), nas quais as plantas são prejudicadas pela dificuldade de explorar o perfil, já quea camada superficial rapidamenteperdeágua. Segundo Wolf (1975), estudando as relações águasolo em um Latossolo Vermelho-Escuro do Brasil Central, períodos de 8 a 10 dias sem chuva na estação das águas são suficientes para secar o solo até 40 a $60 \mathrm{~cm}$ de profundidade, reduzindo a disponibilidade de água às culturas.

Diversos autores observaram menores val ores de saturação por alumínio em plantio direto. I sso se deve, provavelmente, à movimentação física do calcário, propiciada pelos canais resultantes de raízes mortas e mantidos intactos, quese relacionam também com a continuidade dos poros em plantio direto (Oliveira \& Pavan, 1994; Schaefer et al., 2001). Os resíduos vegetais, presentes nesse sistema, promovem a complexação dos íons $\mathrm{Al}^{3+}$ com as substâncias orgânicas ecom complexos hidrossolúveis, que, segundo Miyazawa et al. (1996), formam compostos de baixa solubilidade, mesmo com o decréscimo do pH do solo (Paiva et al., 1996).

Anderson \& Hendrick (1983) injetaram calcário por via aquosa, na camada de $18-36 \mathrm{~cm}$ no perfil, e observaram boa uniformidade de distribuição e bom desenvolvimento radicular dos cereais testados. Essa forma de calagem segmentada foi avaliada por Kauffman \& Gardner (1978), os quais observaram redução dos sintomas de toxidez de alumínio em raízes de trigo crescendo em limitadas porções de solo quando o cal cário foi misturado com 10 e $30 \%$ do volume total de solo, em relação à testemunha sem cal cário.

Outra alternativa, testada por Pöttker et al. (1995), foi a aplicação de cal cário finamente moído ( Filler) nas linhas de plantio desoja para a produção de grãos. Pelos resultados obtidos, concluíram que essa modalidade pode constituir uma alternativa para a calagem em PD.

O efeito positivo da calagem em aumentar a produção e melhorar a absorção de nutrientes pelo milho foi comprovado por Camargo et al. (1982), Caires et al. (1997) eE rnani et al. (1998). Notrabalho de Ernani et al. (2002), observou-se que a calagem aumentou a produção de milho nos três anos em que foi realizado o experimento, tendo si do esse aumento maior no preparo convencional que no PD, em dois dos três anos considerados. Caires et al. (1997) obtiveram também resultado positivo, testando o efeito da calagem sobre a cultura do milho. Observaram aumento da produção com a incorporação do cal cário, sendo significativamente superior à aplicação do calcário na superfície, sem incorporação.

No entanto, Pöttker \& Ben (1998), Caires et al. $(1999,2000)$ e Moreira et al. (2001) não verificaram incremento na produção de milho com aplicação da calagem ou de métodos de aplicação de cal cário em PD. De modo semelhante, Petrere \& Anghinoni (2001) observaram que o calcário, aplicado em diferentes doses, superficialmente com e sem incor poração, influiu nas características químicas no perfil do solo, mas não alterou o rendimento da seqüência de culturas de verão utilizada (soja-sojamilho-soja). Por sua vez, a ausência de variações no status nutricional das culturas em resposta à calagem, em diferentes sistemas de cultivo, foi observada por Caires et al. (1998) e Moreira et al. (2001).

Esses resultados são explicáveis porque a calagem, mesmo quando superficial, mantém teores suficientes de Ca e M g no sol o eaumenta a absorção de nutrientes (Caires et al., 2001), mesmo que não promova a correção do $\mathrm{Al}^{3+}$ em subsuperfície ou o crescimento deraízes em profundidade. Além disso, ocorre menor efeito tóxico do $\mathrm{Al}^{3+} \mathrm{em} \mathrm{PD}$, resultante da complexação por compostos orgânicos (Miyazawa et al., 1996). Por outro lado, a concentração superficial dos nutrientes ea maior disponibilidade hídrica, resultante da melhor conservação da umidadeem PD, favorecem omel hor desenvol vimento das culturas.

O presente trabal ho teve como objetivo avaliar a influência de diferentes modalidades de aplicação decal cário nos atributos quími cos do solo, no estado nutricional e nas características agronômicas da cultura do milho.

\section{MATERIAL E MÉTODOS}

O experimento foi realizado de outubro de 1998 a maio de 1999, na Estação Experimental do município de Coimbra, pertencente à U niversidade Federal de Viçosa (UFV), em Viçosa, Minas Gerais.

Foi utilizado o Argissolo Vermelho-Amarelo de textura argilosa e topografia plana, cuja análise química é apresentada no quadro 1.

O experimento seguiu um esquema de parcelas subdivididas, tendo, nas parcelas, os cultivares de milho (Zea mays L.) e, nas subparcelas, as modalidades de aplicação de calcário, no delineamento em bl ocos ao acaso, com três repetições. Cada parcela teve área total de $100 \mathrm{~m}^{2}(20 \times 5 \mathrm{~m}) \mathrm{e}$ área útil de $30 \mathrm{~m}^{2}(10 \times 3 \mathrm{~m})$. 
Quadro 1. Análise química da camada de $0-20 \mathrm{~cm}$ de profundidade do solo utilizado no experimento, classificado como Argissolo Vermelho-Amarelo

\begin{tabular}{|c|c|c|c|c|c|c|c|c|c|c|c|}
\hline Bloco & $\begin{array}{l}\mathrm{pH}_{\mathrm{H}_{2} \mathrm{O}} \\
(1: 2,5)\end{array}$ & $\mathbf{P}$ & $\mathbf{H}+\mathbf{A} \mathbf{I}$ & $\mathbf{A l}^{3+}$ & $\mathrm{Ca}^{2+}$ & $\mathbf{M g}^{2+}$ & $\mathbf{K}^{+}$ & CTC $_{\text {total }}$ & $\mathbf{v}$ & $\mathbf{m}$ & Textura \\
\hline & & $\mathrm{mg} \mathrm{dm}^{-3}$ & 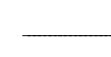 & 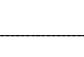 & $-\mathrm{cmo}$ & $n^{-3}-$ & 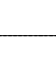 & - & \multicolumn{2}{|c|}{$-\%$} & \\
\hline I & 5,1 & 16 & 5,93 & 0,2 & 1,9 & 0,6 & 86 & 8,66 & 31 & 7 & Argilosa \\
\hline II & 4,7 & 27 & 6,86 & 0,5 & 2,0 & 0,5 & 88 & 9,53 & 28 & 16 & Argilosa \\
\hline III & 4,7 & 11 & 6,86 & 0,7 & 1,2 & 0,4 & 86 & 8,74 & 21 & 27 & Argilosa \\
\hline
\end{tabular}

Os tratamentos aplicados nas parcelas foram: milho híbrido duplo Z 8447, tolerante ao $\mathrm{Al}^{3+}$; variedade de milho AL 25, medianamente sensível ao $\mathrm{Al}^{3+}$, e híbrido duplo AG 122 , muito sensível ao $\mathrm{Al}^{3+}$. Os cultivares foram sel ecionados com base no índice de tolerância relativa a alumínio, segundo Furlani (1995).

Os tratamentos aplicados nas subparcelas foram: (1) testemunha sem aplicação de cal cário; (2) cal cário aplicado ao longo do perfil do solo no sulco de semeadura, na dosagem total recomendada, com base no método de saturação por bases; a quantidade total aplicada foi de $20 \%$ da dose recomendada, visto que foram utilizadas duas faixas de $10 \mathrm{~cm}$ de largura e $20 \mathrm{~cm}$ de profundidade, correspondendo a $20 \%$ da área; (3) calcário aplicado a lanço na superfície do solo, com $50 \%$ da dosagem total recomendada; (4) cal cário aplicado ao longo do perfil do solo no sulco de semeadura, na dosagem total recomendada, com base no método de saturação por bases; a quantidade total aplicada foi $20 \%$ da dose recomendada, uma vez queseutilizaram duas faixas de $10 \mathrm{~cm}$ de largura e $20 \mathrm{~cm}$ de profundidade, correspondendo a $20 \%$ da área, mais calcário aplicado a lanço na superfície, com $50 \%$ da dosagem total recomendada.

O equipamento para distribuição de cal cário ao longo do perfil do solo no sulco de semeadura e o método foram desenvolvidos no Setor deAgronomia do Departamento de Fitotecnia da UFV.

Em teste preliminar, por meio de medições na superfície do solo e na abertura de trincheiras, observou-se a distribuição do cal cário em $10 \mathrm{~cm}$ de largura eaté $30 \mathrm{~cm}$ de profundidade de sol o em cada linha pelo mecanismo e método desenvolvidos. Com base nessa distribuição, calcul ou-sea quantidade de calcário para os tratamentos que envolviam calagem no sulco, supondo a correção de $20 \%$ da área total a ser utilizada, com os sul cadores espaçados de 0,50 m. No teste, foram determinadas as quantidades mínimas e máximas aplicadas pelo equi pamento.

A necessidade de calcário foi determinada pelo método da saturação por bases, sendo recomendados $3,6,4,3$ e 4,8 t ha-1 nos blocos um, dois e três, respectivamente. Nos tratamentos em que o cal cário foi aplicado ao longo do perfil do sulco, com o equipamento desenvolvido, houve coincidência da semeadura com os sulcos de aplicação do cal cário, que estavam distanciados $1 \mathrm{~m}$ entre si, ficando um sulco de aplicação de calcário entre eles, já que a aplicação de calcário foi feita em sul cos distanciados entre si de 0,50 m. O calcário aplicado apresentava as seguintes características químicas: $\mathrm{CaO}=26 \%$; $\mathrm{MgO}=14 \% ; \mathrm{PN}=81,2 \% ; \mathrm{PRNT}=76,0 \%$. A aplicação do cal cário ocorreu no dia 17/11/1998, e o plantio da cultura do milho dois dias após. O espaçamento utilizado foi de $1 \mathrm{~m}$ entre sulcos, mantendo-se seis plantas por $m$ linear, constituindo uma população de 60.000 plantas ha-1.

A adubação no plantio foi feita com $250 \mathrm{~kg} \mathrm{ha}^{-1}$ da fórmula 4-14-8 e a adubação nitrogenada em cobertura foi realizada quando o milho apresentava quatro fol has, com a aplicação de $30 \mathrm{~kg} \mathrm{ha}^{-1}$ de N, na forma desulfato deamônio. Efetuou-sea dessecação das plantas daninhas antes do plantio com o herbicida glyphosate, na dose de $2,5 \mathrm{~L} \mathrm{ha}^{-1}$, e, para controlar as plantas daninhas em pós-emergência, aplicou-sea mistura de atrazine + nicossulfuron, na dosagem de $1.250+40 \mathrm{~g}$ do ingrediente ativo ha-1.

O material para as análises químicas do solo foi col etado aos 30 e 150 dias da calagem. As amostras de sol o foram coletadas a partir do centro da linha de semeadura (para todos os tratamentos), e, perpendicularmente a esta, nas distâncias de 5, 10, 15 e $25 \mathrm{~cm}$ em um de seus lados, retiradas na área útil de cada parcela. Para cada distância foram col etadas amostras em cinco profundidades: 0-2,5; 2,5-5; 5-10; 10-15; e 15-20 cm. Na amostragem realizada 150 dias da calagem, foram incluídas amostras retiradas no sulco de semeadura, que coincidiu com o sulco de calagem (distância zero). As análises de $\mathrm{pH}$ e Al e Ca e Mg trocáveis foram efetuadas de acordo com o método descrito por Defelipo \& Ribeiro (1981).

A coleta de folhas para avaliação do estado nutricional das plantas de milho foi feita na época do florescimento, 67 dias após a emergência das plantas. Foram utilizadas folhas completamente 
desenvolvidas, situadas imediatamente abaixo e opostas à primeira espiga. De cada parcela foram retiradas 20 fol has de plantas situadas na área útil da parcela experimental (Malavolta et al., 1989). U ma amostra de $0,5 \mathrm{~g}$ foi digerida pela mistura nitroperclórica para determinação de P, K, Ca, Mg, $\mathrm{Cu}, \mathrm{Fe}, \mathrm{Mn}$ e Zn. A quantificação dos nutrientes foi feita de acordo com os seguintes métodos: fósforo, pel o método col orimétrico da vitamina $\mathrm{C}$, de acordo com Braga \& Defelipo (1974); potássio, pelo método da fotometria de chama, e cálcio, magnésio, cobre, ferro, manganês e zinco, pelo método da espectrofotometria de absorção atômica (AOAC, 1975).

Foram avaliadas as seguintes características agronômicas: estandefinal, número de espigas ha-1, altura de planta, altura da espiga superior, peso de espiga e produtividade de grãos. Os val ores médios de al tura de planta e de inserção da primeira espiga foram obtidos por meio da amostragem de quatro plantas ao acaso, feita na área útil de cada parcela. O número de espigas por hectare, estande final, peso de espigas e produtividade de grãos foram obtidos, por ocasião da col heita, na área útil em cada parcela. Os valores encontrados foram transformados em unidades por hectare. Para os parâmetros peso de grãos e peso de espigas, corrigiu-se a umidade para $13 \%$.

Os dados foram submeti dos à análise de variância. As médias foram comparadas por meio do teste de Tukey a $5 \%$.

\section{RESULTADOS E DISCUSSÃO}

\section{Atributos químicos do solo}

Os valores de $\mathrm{pH}$ e $\mathrm{Ca}, \mathrm{Mg}$ e $\mathrm{Al}$ trocáveis não foram significativamente afetados pelos cultivares e interação cultivares $x$ modalidades de aplicação de calcário e, por essa razão, foram discutidas separadamente.

$\mathrm{Na}$ profundidade de $0-2,5 \mathrm{~cm}$, em todas as distâncias laterais, nas amostragens aos 30 e 150 dias, os tratamentos que envolveram a aplicação de cal cário na superfície (tratamentos 3 e 4) foram mais eficientes na correção da acidez, com valores de $\mathrm{pH}$ eteores de $\mathrm{Ca}^{2+} \mathrm{eM} \mathrm{g}^{2+}$ mais el evados e teores de Al trocável mais baixos (Quadros 2, 3, 4 e 5). A aplicação de cal cário no sulco (tratamento 2), isol adamente, não diferiu da testemunha (tratamento 1), na camada de 0-2,5 cm. Observou-se que a aplicação do calcário na superfície do solo foi eficiente em corrigir a acidez e fornecer $\mathrm{Ca}^{2+}$ e $\mathrm{Mg}^{2+}$ até $2,5 \mathrm{~cm}$ de profundidade, o que se mostrou coerente com os resultados obtidos por Hargrove et al . (1982), Caires et al. (1998; 1999; 2000) e Moreira et al. (2001). Nos trabal hos em quefoi constatada a movimentação do calcário para a subsuperfície (Oliveira \& Pavan,
1994; Caires et al., 1998; 2000), a camada superficial em PD, coma calagem em superfície, revelou condições adequadas ao desenvolvimento das plantas, no tocante a $\mathrm{pH}, \mathrm{Al}$ trocável e teor de nutrientes.

Na profundidade de 2,5-5 cm, observou-se que o tratamento 4 apresentou valores de $\mathrm{pH}$ e teores de Ca eMgsuperiores ou iguais aos dos demais tratamentos em todas as distâncias laterais. Na linha de plantio (distância 0), na amostragem aos 150 dias, o $\mathrm{pH}, \mathrm{Ca}^{2+} \mathrm{e} \mathrm{Mg}^{2+}$, no tratamento 4, apresentaram val ores sempre superiores ou iguais estatisticamente aos dos demais tratamentos eAl trocável mais baixo. Tal resultado comprova a eficiência da aplicação do calcário ao longo do perfil do sulco, junto com a calagem na superfície, na elevação do pH e redução do $\mathrm{Al}^{3+}$, e distribuição de $\mathrm{Ca}^{2+} \mathrm{eMg}^{2+}$.

Vale destacar que tal fato é mais bem observado a partir da profundidade de $5-10 \mathrm{~cm}$, principalmente até $5 \mathrm{~cm}$ da linha, na amostragem aos 150 dias. Pode-se observar, a partir da profundidade de 2,5$5 \mathrm{~cm}$, redução nos valores de $\mathrm{pH}, \mathrm{Ca}^{2+}$ e $\mathrm{Mg}^{2+} \mathrm{e}$ el evação dos teores de $\mathrm{Al}^{3+}$ em todos os tratamentos em relação aos obtidos na profundidade de $0-2,5 \mathrm{~cm}$. A baixa mobilidade do cal cário no perfil do solo foi responsável pelos resultados obtidos, confirmando as observações de Pöttker \& Ben (1998).

Nota-se que, a partir de $10 \mathrm{~cm}$ de distância lateral e 5-10 cm de profundidade, os tratamentos tendem a se igualar, indicando o efeito da calagem restrito à região mais próxima onde foi efetuada. Todavia, mesmo não diferindo significativamente, observa-se que, em valores absolutos, o tratamento 4, a partir da profundidade de $2,5-5 \mathrm{~cm}$, em praticamentetodas as distâncias laterais, apresentou os maiores valores de $\mathrm{pH}$ e teores $\mathrm{Ca}^{2+} \mathrm{e} \mathrm{Mg}^{2+}$, e os menores teores de $\mathrm{Al}^{3+}$ no solo, em relação aos demais tratamentos, nas duas amostragens, indicando ser a combinação da aplicação superficial com a distribuiç̧ão do cal cário no perfil do solo a mel hor opção entre os tratamentos testados para a correção do solo.

Tal fato é corroborado por ter a calagem na superfície (tratamento 3) apresentado os maiores teores de alumínio no solo, em praticamente todo o perfil, abaixo da camada de 2,5-5 cm. Mesmo com efeito restrito a $5 \mathrm{~cm}$ de distância lateral, a aplicação no sulco promove mel hores condições para enraizamento emaior tolerância a déficits hídricos (Kauffman \& Gardner, 1978). A ausência de diferenças significativas, em diversas combinações de profundidade e distância lateral, deveu-se ao rigor do teste em detectar diferenças estatísticas entre as médias de tratamentos. Além disso, como nenhum tratamento envolveu incorporação do calcário ao volume total do solo (a incorporação ocorreu apenas na linha de semeadura, nos tratamentos 2 e 4 ) eter a amostragem promovido a retirada de amostras até $25 \mathrm{~cm}$ de distância da linha desemeadura, énatural que, como aumento da distância e da profundidade de amostragem, os tratamentos tendam a não diferir entre si. 
Apesar da redução do $\mathrm{pH}$ observada com o aumento da profundidade, de modo geral, nos tratamentos 2 e 4, a variação dos valores de pH do sol o em todo o perfil, em todas as distâncias laterais, foi menor quando comparada com o tratamento que recebeu apenas calagem na superfície. Esses resultados evidenciaram a uniformidade na distribuição do cal cário aplicado ao longo do perfil do solo no sulco de semeadura (Quadro 2).

Para o cálcio (Quadro 3), verificou-se que os teores mais el evados, de modo geral, foram obtidos na linha, principal mente nos tratamentos com a aplicação de calcário ao longo do perfil do solo e no sulco de semeadura, os quais também apresentaram maior uniformidade de distribuição de cálcio em todo o perfil amostrado, estando de acordo com os resultados obtidos por Anderson \& Hendrick (1983), que injetaram calcário em suspensão aquosa no sulco, por meio de um subsolador. O tratamento 4 foi o mais eficiente no fornecimento de cálcio em, praticamente, todo o perfil amostrado.

O comportamento do magnésio foi semelhante ao do cál cio, tendo a utilização de cal cário dol omítico contribuído para maior fornecimento de magnésio, como observaram Santos \& Siqueira (1996), emaior número de diferenças significativas entre os tratamentos avaliados (Quadro 4). Percebe-se também que aos 150 dias os teores de magnésio foram, em sua maioria, superiores aos encontrados aos 30 dias. Apesar de sua absorção pelas plantas, sua maior disponibilidade promovida pela calagem com o tempo talvez possa explicar os teores mais elevados na amostragem realizada aos 150 dias. Esses resultados indicaram que a combinação da modal idade de apl icação do cal cário ao longo do perfil do sulco e a aplicação superficial (tratamento 4) foi efetiva no fornecimento de $\mathrm{Mg}^{2+}$ e superior às demais, enquanto a aplicação somente na superfície concentrou o $\mathrm{Mg}^{2+}$ nos $5 \mathrm{~cm}$ superficiais do solo, concordando com os resultados obtidos por Caires et al. (1998) e Moreira et al. (2001).

Para o alumínio (Quadro 5), observou-se que, na maioria dos casos, os teores desse el emento no solo foram superiores na amostragem realizada aos 150 dias, quando comparados com a amostragem feita aos 30 dias, como também observado para magnésio. Santos \& Siqueira (1996) obtiveram resultados

Quadro 2. Valores médios de pH em água (1:2,5) nos diferentes tratamentos amostrados aos 30 e 150 dias da calagem, nas distâncias laterais a partir da linha de semeadura (0, 5, 10, 15 e $25 \mathrm{~cm})$ e nas profundidades de 0-2,5, 2,5-5, 5-10, 10-15 e 15-20 cm

\begin{tabular}{|c|c|c|c|c|c|c|c|c|c|c|c|}
\hline \multirow{4}{*}{ Profundidade } & \multirow{4}{*}{ Tratamento ${ }^{(1)}$} & \multicolumn{10}{|c|}{ Distância lateral (cm) } \\
\hline & & \multicolumn{2}{|r|}{0} & \multicolumn{2}{|c|}{5} & \multicolumn{2}{|c|}{10} & \multicolumn{2}{|c|}{15} & \multicolumn{2}{|c|}{25} \\
\hline & & & & & & & & & & & \\
\hline & & 30 & 150 & 30 & 150 & 30 & 150 & 30 & 150 & 30 & 150 \\
\hline \multicolumn{12}{|l|}{$\mathrm{cm}$} \\
\hline $0-2,5$ & $\begin{array}{l}\text { Testemunha } \\
\text { Sulco } \\
\text { Superfície } \\
\text { Sulco + superf. }\end{array}$ & $\begin{array}{l}- \\
- \\
- \\
-\end{array}$ & $\begin{array}{l}4,77 \mathrm{~b} \\
4,87 \mathrm{~b} \\
5,65 \mathrm{~b} \\
6,06 \mathrm{a}\end{array}$ & $\begin{array}{l}5,16 \mathrm{~b} \\
4,89 \mathrm{~b} \\
5,45 \mathrm{~b} \\
6,19 \mathrm{a}\end{array}$ & $\begin{array}{l}5,13 \mathrm{~b} \\
4,93 \mathrm{~b} \\
6,29 \mathrm{a} \\
5,59 \mathrm{ab}\end{array}$ & $\begin{array}{l}5,09 \mathrm{~b} \\
5,03 \mathrm{~b} \\
5,95 \mathrm{a} \\
5,93 \mathrm{a}\end{array}$ & $\begin{array}{l}5,08 \mathrm{ab} \\
4,83 \mathrm{~b} \\
5,91 \mathrm{a} \\
5,84 \mathrm{a}\end{array}$ & $\begin{array}{l}5,00 \mathrm{~b} \\
5,16 \mathrm{ab} \\
5,88 \mathrm{a} \\
5,81 \mathrm{a}\end{array}$ & $\begin{array}{l}4,99 \mathrm{~b} \\
4,92 \mathrm{~b} \\
5,64 \mathrm{a} \\
6,10 \mathrm{a}\end{array}$ & $\begin{array}{l}5,29 \mathrm{~b} \\
4,95 \mathrm{~b} \\
5,94 \mathrm{a} \\
5,55 \mathrm{ab}\end{array}$ & $\begin{array}{l}5,17 b \\
5,05 b \\
6,15 a \\
6,22 a\end{array}$ \\
\hline $2,5-5$ & $\begin{array}{l}\text { Testemunha } \\
\text { Sulco } \\
\text { Superfície } \\
\text { Sulco + superf. }\end{array}$ & $\begin{array}{l}- \\
- \\
- \\
-\end{array}$ & $\begin{array}{l}4,70 \mathrm{~b} \\
4,75 \mathrm{~b} \\
4,99 \mathrm{~b} \\
5,92 \mathrm{a}\end{array}$ & $\begin{array}{l}4,71 \mathrm{~b} \\
4,69 \mathrm{~b} \\
4,57 \mathrm{~b} \\
5,61 \mathrm{a}\end{array}$ & $\begin{array}{l}4,78 \mathrm{a} \\
4,82 \mathrm{a} \\
4,99 \mathrm{a} \\
5,16 \mathrm{a}\end{array}$ & $\begin{array}{l}4,74 \mathrm{~b} \\
4,83 \mathrm{~b} \\
5,11 \mathrm{ab} \\
5,49 \mathrm{a}\end{array}$ & $\begin{array}{l}4,79 \mathrm{~b} \\
4,75 \mathrm{~b} \\
4,86 \mathrm{~b} \\
5,58 \mathrm{a}\end{array}$ & $\begin{array}{l}4,80 a \\
4,88 a \\
4,98 a \\
5,28 a\end{array}$ & $\begin{array}{l}4,47 \mathrm{~b} \\
4,78 \mathrm{~b} \\
4,81 \mathrm{~b} \\
5,72 \mathrm{a}\end{array}$ & $\begin{array}{l}4,84 \mathrm{a} \\
4,79 \mathrm{a} \\
4,79 \mathrm{a} \\
5,31 \mathrm{a}\end{array}$ & $\begin{array}{l}4,95 \mathrm{a} \\
4,97 \mathrm{a} \\
5,15 \mathrm{a} \\
5,55 \mathrm{a}\end{array}$ \\
\hline $10-15$ & $\begin{array}{l}\text { Testemunha } \\
\text { Sulco } \\
\text { Superfície } \\
\text { Sulco + superf. }\end{array}$ & $\begin{array}{l}- \\
- \\
- \\
-\end{array}$ & $\begin{array}{l}4,55 a b \\
4,76 a b \\
4,28 b \\
5,06 a\end{array}$ & $\begin{array}{l}4,57 \mathrm{a} \\
4,69 \mathrm{a} \\
4,41 \mathrm{a} \\
4,98 \mathrm{a}\end{array}$ & $\begin{array}{l}4,72 \mathrm{~b} \\
5,17 \mathrm{ab} \\
4,53 \mathrm{~b} \\
5,57 \mathrm{a}\end{array}$ & $\begin{array}{l}4,56 \mathrm{a} \\
4,72 \mathrm{a} \\
4,36 \mathrm{a} \\
4,79 \mathrm{a}\end{array}$ & $\begin{array}{l}4,73 a \\
4,83 a \\
4,60 a \\
5,00 a\end{array}$ & $\begin{array}{l}4,59 a \\
4,70 a \\
4,40 a \\
4,72 a\end{array}$ & $\begin{array}{l}4,28 \mathrm{a} \\
4,76 \mathrm{a} \\
4,53 \mathrm{a} \\
5,05 \mathrm{a}\end{array}$ & $\begin{array}{l}4,52 \mathrm{a} \\
4,67 \mathrm{a} \\
4,47 \mathrm{a} \\
5,03 \mathrm{a}\end{array}$ & $\begin{array}{l}4,76 \mathrm{a} \\
5,03 \mathrm{a} \\
4,43 \mathrm{a} \\
5,11 \mathrm{a}\end{array}$ \\
\hline $15-20$ & $\begin{array}{l}\text { Testemunha } \\
\text { Sulco } \\
\text { Superfície } \\
\text { Sulco + superf. }\end{array}$ & $\begin{array}{l}- \\
- \\
- \\
-\end{array}$ & $\begin{array}{l}4,67 \mathrm{a} \\
4,72 \mathrm{a} \\
4,33 \mathrm{a} \\
4,98 \mathrm{a}\end{array}$ & $\begin{array}{l}4,59 a b \\
4,60 a b \\
4,39 b \\
4,86 a\end{array}$ & $\begin{array}{l}4,75 a b \\
4,87 a b \\
4,58 \mathrm{~b} \\
5,16 \mathrm{a}\end{array}$ & $\begin{array}{l}4,70 \mathrm{a} \\
4,61 \mathrm{a} \\
4,46 \mathrm{a} \\
4,75 \mathrm{a}\end{array}$ & $\begin{array}{l}4,84 \mathrm{a} \\
4,95 \mathrm{a} \\
4,63 \mathrm{a} \\
5,07 \mathrm{a}\end{array}$ & $\begin{array}{l}4,58 \mathrm{a} \\
4,68 \mathrm{a} \\
4,51 \mathrm{a} \\
4,86 \mathrm{a}\end{array}$ & $\begin{array}{l}4,81 \text { a } \\
4,77 \mathrm{a} \\
4,62 \mathrm{a} \\
5,20 \mathrm{a}\end{array}$ & $\begin{array}{l}4,52 \mathrm{a} \\
4,57 \mathrm{a} \\
4,51 \mathrm{a} \\
4,64 \mathrm{a}\end{array}$ & $\begin{array}{l}4,83 \mathrm{a} \\
4,79 \mathrm{a} \\
4,81 \mathrm{a} \\
4,95 \mathrm{a}\end{array}$ \\
\hline
\end{tabular}

\footnotetext{
(1) Testemunha sem calagem; 2) cal cário aplicado ao longo do perfil do sol o no sulco de plantio; 3) cal cário aplicado na superfície sem incorporação; 4) cal cário aplicado ao longo do perfil do solo, no sulco de plantio, mais cal cário na superfície, sem incorporação. As médias seguidas de uma mesma letra na coluna, considerando a mesma distância, profundidade e amostragem, não diferem significativamente entre si, pelo teste de Tukey a $5 \%$.
} 
Quadro 3. Valores médios de cálcio trocável nos diferentes tratamentos amostrados aos 30 e 150 dias da calagem, nas distâncias laterais a partir da linha de semeadura $(0,5,10,15$ e $25 \mathrm{~cm})$ e nas profundidades de $0-2,5,2,5-5,5-10,10-15$ e $15-20 \mathrm{~cm}$

\begin{tabular}{|c|c|c|c|c|c|c|c|c|c|c|c|}
\hline \multirow{3}{*}{ Profundidade } & \multirow{3}{*}{ Tratamento(1) } & \multicolumn{10}{|c|}{ Distância lateral (cm) } \\
\hline & & \multicolumn{2}{|r|}{$\mathbf{0}$} & \multicolumn{2}{|c|}{5} & \multicolumn{2}{|c|}{10} & \multicolumn{2}{|c|}{15} & \multicolumn{2}{|c|}{25} \\
\hline & & & & & \multicolumn{7}{|c|}{ Dias após calagem } \\
\hline & & 30 & 150 & 30 & 150 & 30 & 150 & 30 & 150 & 30 & 150 \\
\hline $\mathrm{cm}$ & & & & & & $-c$ & $l_{c} d m^{-3}$ & & & & \\
\hline $0-2,5$ & $\begin{array}{l}\text { Testemunha } \\
\text { Sulco } \\
\text { Superfície } \\
\text { Sulco + superf. }\end{array}$ & $\begin{array}{l}- \\
- \\
- \\
-\end{array}$ & $\begin{array}{l}2,33 \mathrm{~b} \\
2,67 \mathrm{~b} \\
4,19 \mathrm{a} \\
3,61 \mathrm{a}\end{array}$ & $\begin{array}{l}2,04 \mathrm{~b} \\
1,73 \mathrm{~b} \\
2,63 \mathrm{ab} \\
3,38 \mathrm{a}\end{array}$ & $\begin{array}{l}1,58 \mathrm{bc} \\
1,45 \mathrm{c} \\
3,20 \mathrm{a} \\
2,50 \mathrm{ab}\end{array}$ & $\begin{array}{l}1,66 \mathrm{~b} \\
1,79 \mathrm{~b} \\
3,11 \mathrm{a} \\
2,90 \mathrm{a}\end{array}$ & $\begin{array}{l}1,52 \mathrm{~b} \\
1,37 \mathrm{~b} \\
2,67 \mathrm{a} \\
2,46 \mathrm{a}\end{array}$ & $\begin{array}{l}1,73 \mathrm{c} \\
1,79 \mathrm{bc} \\
3,01 \mathrm{a} \\
2,81 \mathrm{ab}\end{array}$ & $\begin{array}{l}1,51 \mathrm{~b} \\
1,57 \mathrm{~b} \\
2,59 \mathrm{a} \\
2,75 \mathrm{a}\end{array}$ & $\begin{array}{l}1,91 \mathrm{ab} \\
1,60 \mathrm{~b} \\
2,70 \mathrm{a} \\
2,24 \mathrm{ab}\end{array}$ & $\begin{array}{l}1,58 \mathrm{~b} \\
1,51 \mathrm{~b} \\
2,91 \mathrm{a} \\
2,92 \mathrm{a}\end{array}$ \\
\hline $2,5-5$ & $\begin{array}{l}\text { Testemunha } \\
\text { Sulco } \\
\text { Superfície } \\
\text { Sulco + superf. }\end{array}$ & $\begin{array}{l}- \\
- \\
- \\
-\end{array}$ & $\begin{array}{l}2,63 \mathrm{~b} \\
3,82 \mathrm{ab} \\
4,20 \mathrm{ab} \\
4,69 \mathrm{a}\end{array}$ & $\begin{array}{l}1,76 \mathrm{~b} \\
1,42 \mathrm{~b} \\
1,63 \mathrm{~b} \\
3,29 \mathrm{a}\end{array}$ & $\begin{array}{l}1,30 \mathrm{~b} \\
1,47 \mathrm{ab} \\
1,49 \mathrm{ab} \\
2,06 \mathrm{a}\end{array}$ & $\begin{array}{l}1,36 \mathrm{~b} \\
1,62 \mathrm{~b} \\
1,82 \mathrm{ab} \\
2,38 \mathrm{a}\end{array}$ & $\begin{array}{l}1,15 a \\
1,36 a \\
1,35 a \\
2,09 a\end{array}$ & $\begin{array}{l}1,41 \mathrm{a} \\
1,61 \mathrm{a} \\
1,67 \mathrm{a} \\
2,06 \mathrm{a}\end{array}$ & $\begin{array}{l}1,26 \mathrm{~b} \\
1,58 \mathrm{~b} \\
1,26 \mathrm{~b} \\
2,47 \mathrm{a}\end{array}$ & $\begin{array}{l}1,55 a \\
1,49 a \\
1,67 a \\
2,40 a\end{array}$ & $\begin{array}{l}1,38 \mathrm{~b} \\
1,50 \mathrm{~b} \\
1,57 \mathrm{~b} \\
2,30 \mathrm{a}\end{array}$ \\
\hline $5-10$ & $\begin{array}{l}\text { Testemunha } \\
\text { Sulco } \\
\text { Superfície } \\
\text { Sulco + superf. }\end{array}$ & $\begin{array}{l}- \\
- \\
- \\
-\end{array}$ & $\begin{array}{l}2,01 \mathrm{ab} \\
2,26 \mathrm{ab} \\
1,95 \mathrm{~b} \\
3,45 \mathrm{a}\end{array}$ & $\begin{array}{l}1,30 \mathrm{a} \\
1,75 \mathrm{a} \\
1,51 \mathrm{a} \\
2,29 \mathrm{a}\end{array}$ & $\begin{array}{l}1,50 \mathrm{~b} \\
1,60 \mathrm{ab} \\
1,23 \mathrm{~b} \\
2,27 \mathrm{a}\end{array}$ & $\begin{array}{l}1,48 \mathrm{a} \\
1,38 \mathrm{a} \\
1,46 \mathrm{a} \\
1,77 \mathrm{a}\end{array}$ & $\begin{array}{l}1,26 \mathrm{a} \\
1,43 \mathrm{a} \\
1,28 \mathrm{a} \\
1,76 \mathrm{a}\end{array}$ & $\begin{array}{l}1,49 a \\
1,47 a \\
1,28 a \\
1,80 a\end{array}$ & $\begin{array}{l}1,56 \mathrm{a} \\
1,57 \mathrm{a} \\
1,09 \mathrm{a} \\
1,69 \mathrm{a}\end{array}$ & $\begin{array}{l}1,33 \mathrm{~b} \\
1,44 \mathrm{ab} \\
1,41 \mathrm{ab} \\
2,54 \mathrm{a}\end{array}$ & $\begin{array}{l}1,27 a b \\
1,31 a b \\
1,17 b \\
1,78 a\end{array}$ \\
\hline $10-15$ & $\begin{array}{l}\text { Testemunha } \\
\text { Sulco } \\
\text { Superfície } \\
\text { Sulco + superf. }\end{array}$ & $\begin{array}{l}- \\
- \\
- \\
-\end{array}$ & $\begin{array}{l}1,76 a b \\
2,23 a b \\
1,50 \mathrm{~b} \\
2,57 \mathrm{a}\end{array}$ & $\begin{array}{l}1,49 a \\
1,58 \mathrm{a} \\
1,31 \mathrm{a} \\
2,08 \mathrm{a}\end{array}$ & $\begin{array}{l}1,43 \mathrm{~b} \\
2,10 \mathrm{ab} \\
1,26 \mathrm{~b} \\
2,84 \mathrm{a}\end{array}$ & $\begin{array}{l}1,55 \mathrm{a} \\
1,74 \mathrm{a} \\
1,31 \mathrm{a} \\
1,80 \mathrm{a}\end{array}$ & $\begin{array}{l}1,52 \mathrm{ab} \\
1,52 \mathrm{ab} \\
1,31 \mathrm{~b} \\
2,11 \mathrm{a}\end{array}$ & $\begin{array}{l}1,50 \mathrm{a} \\
1,85 \mathrm{a} \\
1,28 \mathrm{a} \\
1,61 \mathrm{a}\end{array}$ & $\begin{array}{l}1,47 \mathrm{a} \\
1,59 \mathrm{a} \\
1,10 \mathrm{a} \\
1,64 \mathrm{a}\end{array}$ & $\begin{array}{l}1,62 \mathrm{a} \\
1,53 \mathrm{a} \\
1,35 \mathrm{a} \\
2,25 \mathrm{a}\end{array}$ & $\begin{array}{l}1,42 \mathrm{a} \\
1,77 \mathrm{a} \\
1,17 \mathrm{a} \\
1,80 \mathrm{a}\end{array}$ \\
\hline $15-20$ & $\begin{array}{l}\text { Testemunha } \\
\text { Sulco } \\
\text { Superfície } \\
\text { Sulco + superf. }\end{array}$ & $\begin{array}{l}- \\
- \\
- \\
-\end{array}$ & $\begin{array}{l}1,78 \mathrm{ab} \\
2,13 \mathrm{ab} \\
1,41 \mathrm{~b} \\
2,35 \mathrm{a}\end{array}$ & $\begin{array}{l}1,58 \mathrm{ab} \\
1,60 \mathrm{ab} \\
1,32 \mathrm{~b} \\
2,01 \mathrm{a}\end{array}$ & $\begin{array}{l}1,52 \mathrm{~b} \\
1,71 \mathrm{ab} \\
1,30 \mathrm{~b} \\
2,24 \mathrm{a}\end{array}$ & $\begin{array}{l}1,63 \mathrm{a} \\
1,69 \mathrm{a} \\
1,41 \mathrm{a} \\
1,83 \mathrm{a}\end{array}$ & $\begin{array}{l}1,52 a b \\
1,59 a b \\
1,27 b \\
2,28 a\end{array}$ & $\begin{array}{l}1,51 \mathrm{a} \\
1,53 \mathrm{a} \\
1,44 \mathrm{a} \\
2,12 \mathrm{a}\end{array}$ & $\begin{array}{l}1,52 \mathrm{a} \\
1,60 \mathrm{a} \\
1,15 \mathrm{a} \\
1,75 \mathrm{a}\end{array}$ & $\begin{array}{l}1,51 \mathrm{a} \\
1,50 \mathrm{a} \\
1,44 \mathrm{a} \\
1,68 \mathrm{a}\end{array}$ & $\begin{array}{l}1,47 \mathrm{a} \\
1,35 \mathrm{a} \\
1,44 \mathrm{a} \\
1,66 \mathrm{a}\end{array}$ \\
\hline
\end{tabular}

(1) Testemunha sem calagem; 2) cal cário aplicado ao longo do perfil do sol o no sulco de plantio; 3) cal cário aplicado na superfície sem incorporação; 4) cal cário aplicado ao longo do perfil do solo, no sulco de plantio, mais cal cário na superfície, sem incorporação. As médias seguidas de uma mesma letra na coluna, considerando a mesma distância, profundidade e amostragem, não diferem significativamente entre si, pelo teste de Tukey a $5 \%$.

semelhantes. Eles encontraram que o teor de alumínio do solo foi maior após a instalação do experimento, em comparação com o val or encontrado anteriormente. $\mathrm{O}$ uso de fertilizantes nitrogenados (Moreira et al. (2001) e a manutenção dos restos culturais na superfície geram acidez do sol o, el evando os teores de alumínio pela sua solubilização.

Os resultados obtidos neste trabal ho concordam com os obtidos por Pöttker \& Ben (1998) e Moreira et al. (2001), quanto ao efeito limitado da calagem sem incorporação aos $5 \mathrm{~cm}$ superficiais do solo, e discordam dos resultados de al guns pesquisadores, que constataram o efeito da calagem em superfície até mai ores profundidades (Caires et al., 1998; 1999; 2000). No PD, microclima e certas características de solo são diferentes, quando comparados com o preparo convencional. Schaefer et al. (2001) verificaram que, no sistema PD, ocorre continuidade dos poros, o que contribui para movimentação física do calcário, podendo atingir a subsuperfície e, segundo Miyazawa et al. (1996), a formação de compostos hidrossolúveis pode ser responsável pela complexação do Al em subsuperfície.
Os tratamentos que envolveram a calagem ao longo do perfil do sulco (tratamentos 3 e 4 ) apresentaram maior uniformidade nas características avaliadas, até $5 \mathrm{~cm}$ da linha de plantio, enquanto a aplicação de calcário na superfície gerou um gradiente no perfil, com redução do pH, Ca e Mg e el evação do Al, abaixo dos $5 \mathrm{~cm}$ superficiais (Quadros 2 a 5). Resultados semelhantes foram obtidos por Pöttker \& Ben (1998), Moreira et al. (2001) e Petrere \& Anghinoni (2001).

A aplicação de cal cário na superfície do solo, sem incorporação, teve efeito restrito às camadas superficiais, sendoa aplicação combinada de cal cário na superfície e ao longo do perfil a mais eficiente na correção da acidez e redução do teor do alumínio trocável, bem como no fornecimento de cálcio e magnésio, com efeitos positivos até $20 \mathrm{~cm}$ de profundidade, nas proximidades da linha de aplicação do calcário.

\section{Análise do tecido foliar}

O teor de nutrientes no tecido foliar das plantas de milho não foi significativamente afetado pela 
Quadro 4. Valores médios de magnésio trocável nos diferentes tratamentos amostrados aos 30 e 150 dias da calagem, nas distâncias laterais a partir da linha de semeadura (0, 5, 10, 15 e $25 \mathrm{~cm})$ e nas profundidades de 0-2,5, 2,5-5, 5-10, 10-15 e 15-20 cm

\begin{tabular}{|c|c|c|c|c|c|c|c|c|c|c|c|}
\hline \multirow{4}{*}{ Profundidade } & \multirow{4}{*}{ Tratamento $^{(1)}$} & \multicolumn{10}{|c|}{ Distância lateral (cm) } \\
\hline & & \multicolumn{4}{|c|}{$\mathbf{0}$} & \multicolumn{2}{|c|}{10} & \multicolumn{2}{|c|}{15} & \multicolumn{2}{|c|}{25} \\
\hline & & \multicolumn{10}{|c|}{ Dias após calagem } \\
\hline & & 30 & 150 & 30 & 150 & 30 & 150 & 30 & 150 & 30 & 150 \\
\hline $\mathrm{cm}$ & & & & & & $-c$ & $l_{c} d m^{-3}$ & & & & \\
\hline $0-2,5$ & $\begin{array}{l}\text { Testemunha } \\
\text { Sulco } \\
\text { Superfície } \\
\text { Sulco + superf. }\end{array}$ & $\begin{array}{l}- \\
- \\
- \\
-\end{array}$ & $\begin{array}{l}0,58 \mathrm{~b} \\
0,61 \mathrm{~b} \\
1,56 \mathrm{a} \\
1,70 \mathrm{a}\end{array}$ & $\begin{array}{l}0,87 \mathrm{~b} \\
0,87 \mathrm{~b} \\
2,28 \mathrm{a} \\
2,12 \mathrm{ab}\end{array}$ & $\begin{array}{l}0,60 \mathrm{~b} \\
0,49 \mathrm{~b} \\
1,97 \mathrm{a} \\
1,42 \mathrm{a}\end{array}$ & $\begin{array}{l}0,81 \mathrm{~b} \\
0,86 \mathrm{~b} \\
1,97 \mathrm{a} \\
1,74 \mathrm{ab}\end{array}$ & $\begin{array}{l}0,59 \mathrm{~b} \\
0,50 \mathrm{~b} \\
2,00 \mathrm{a} \\
1,54 \mathrm{a}\end{array}$ & $\begin{array}{l}0,75 \mathrm{~b} \\
0,73 \mathrm{~b} \\
1,94 \mathrm{a} \\
1,59 \mathrm{ab}\end{array}$ & $\begin{array}{l}0,56 \mathrm{~b} \\
0,60 \mathrm{~b} \\
1,63 \mathrm{a} \\
1,81 \mathrm{a}\end{array}$ & $\begin{array}{l}1,00 \mathrm{ab} \\
0,72 \mathrm{~b} \\
1,77 \mathrm{a} \\
1,39 \mathrm{ab}\end{array}$ & $\begin{array}{l}0,60 \mathrm{~b} \\
0,57 \mathrm{~b} \\
1,72 \mathrm{a} \\
1,90 \mathrm{a}\end{array}$ \\
\hline $2,5-5$ & $\begin{array}{l}\text { Testemunha } \\
\text { Sulco } \\
\text { Superfície } \\
\text { Sulco + superf. }\end{array}$ & $\begin{array}{l}- \\
- \\
-\end{array}$ & $\begin{array}{l}0,32 \mathrm{~b} \\
0,32 \mathrm{~b} \\
0,74 \mathrm{a} \\
1,06 \mathrm{a}\end{array}$ & $\begin{array}{l}0,64 \mathrm{~b} \\
0,57 \mathrm{~b} \\
0,94 \mathrm{ab} \\
1,62 \mathrm{a}\end{array}$ & $\begin{array}{l}1,30 \mathrm{~b} \\
1,47 \mathrm{ab} \\
1,49 \mathrm{ab} \\
2,06 \mathrm{a}\end{array}$ & $\begin{array}{l}0,53 \mathrm{~b} \\
0,67 \mathrm{~b} \\
1,09 \mathrm{ab} \\
1,29 \mathrm{a}\end{array}$ & $\begin{array}{l}0,37 \mathrm{~b} \\
0,42 \mathrm{~b} \\
0,61 \mathrm{~b} \\
1,11 \mathrm{a}\end{array}$ & $\begin{array}{l}0,39 \mathrm{c} \\
0,62 \mathrm{bc} \\
0,99 \mathrm{ab} \\
1,11 \mathrm{a}\end{array}$ & $\begin{array}{l}0,38 \mathrm{~b} \\
0,51 \mathrm{~b} \\
0,69 \mathrm{ab} \\
1,38 \mathrm{a}\end{array}$ & $\begin{array}{l}0,59 a \\
0,63 a \\
1,02 a \\
1,32 a\end{array}$ & $\begin{array}{l}0,42 \mathrm{c} \\
0,48 \mathrm{c} \\
0,91 \mathrm{~b} \\
1,25 \mathrm{a}\end{array}$ \\
\hline $5-10$ & $\begin{array}{l}\text { Testemunha } \\
\text { Sulco } \\
\text { Superfície } \\
\text { Sulco + superf. }\end{array}$ & $\begin{array}{l}- \\
- \\
-\end{array}$ & $\begin{array}{l}0,28 \mathrm{~b} \\
0,30 \mathrm{ab} \\
0,41 \mathrm{ab} \\
0,58 \mathrm{a}\end{array}$ & $\begin{array}{l}0,35 a \\
0,50 a \\
0,53 a \\
0,54 a\end{array}$ & $\begin{array}{l}0,28 \mathrm{~b} \\
0,53 a b \\
0,45 a b \\
0,76 a\end{array}$ & $\begin{array}{l}0,43 a \\
0,47 a \\
0,56 a \\
0,74 a\end{array}$ & $\begin{array}{l}0,32 \mathrm{~b} \\
0,40 a b \\
0,50 a b \\
0,75 a\end{array}$ & $\begin{array}{l}0,35 \mathrm{a} \\
0,50 \mathrm{a} \\
0,53 \mathrm{a} \\
0,54 \mathrm{a}\end{array}$ & $\begin{array}{l}0,29 b \\
0,43 a b \\
0,48 a b \\
0,67 a\end{array}$ & $\begin{array}{l}0,32 \mathrm{~b} \\
0,59 \mathrm{~b} \\
0,32 \mathrm{~b} \\
0,96 \mathrm{a}\end{array}$ & $\begin{array}{l}0,30 \mathrm{~b} \\
0,37 \mathrm{~b} \\
0,45 \mathrm{~b} \\
0,82 \mathrm{a}\end{array}$ \\
\hline $10-15$ & $\begin{array}{l}\text { Testemunha } \\
\text { Sulco } \\
\text { Superfície } \\
\text { Sulco + superf. }\end{array}$ & $\begin{array}{l}- \\
- \\
-\end{array}$ & $\begin{array}{l}0,34 \mathrm{a} \\
0,51 \mathrm{a} \\
0,34 \mathrm{a} \\
0,70 \mathrm{a}\end{array}$ & $\begin{array}{l}0,41 \mathrm{a} \\
0,56 \mathrm{a} \\
0,55 \mathrm{a} \\
0,84 \mathrm{a}\end{array}$ & $\begin{array}{l}0,31 \mathrm{~b} \\
0,60 \mathrm{ab} \\
0,40 \mathrm{~b} \\
1,23 \mathrm{a}\end{array}$ & $\begin{array}{l}0,41 \mathrm{a} \\
0,63 \mathrm{a} \\
0,33 \mathrm{a} \\
0,58 \mathrm{a}\end{array}$ & $\begin{array}{l}0,35 \mathrm{~b} \\
0,45 \mathrm{ab} \\
0,43 \mathrm{ab} \\
0,83 \mathrm{a}\end{array}$ & $\begin{array}{l}0,44 \mathrm{a} \\
0,65 \mathrm{a} \\
0,38 \mathrm{a} \\
0,45 \mathrm{a}\end{array}$ & $\begin{array}{l}0,33 \mathrm{a} \\
0,49 \mathrm{a} \\
0,38 \mathrm{a} \\
0,57 \mathrm{a}\end{array}$ & $\begin{array}{l}0,48 a b \\
0,37 \mathrm{~b} \\
0,28 \mathrm{~b} \\
0,63 \mathrm{a}\end{array}$ & $\begin{array}{l}0,32 a \\
0,52 a \\
0,38 a \\
0,86 a\end{array}$ \\
\hline $15-20$ & $\begin{array}{l}\text { Testemunha } \\
\text { Sulco } \\
\text { Superfície } \\
\text { Sulco + superf. }\end{array}$ & $\begin{array}{l}- \\
- \\
-\end{array}$ & $\begin{array}{l}0,40 a b \\
0,60 a b \\
0,33 \mathrm{~b} \\
0,82 \mathrm{a}\end{array}$ & $\begin{array}{l}0,49 a \\
0,61 a \\
0,44 a \\
0,69 a\end{array}$ & $\begin{array}{l}0,35 \mathrm{a} \\
0,51 \mathrm{a} \\
0,36 \mathrm{a} \\
0,88 \mathrm{a}\end{array}$ & $\begin{array}{l}0,58 \mathrm{a} \\
0,78 \mathrm{a} \\
0,44 \mathrm{a} \\
0,57 \mathrm{a}\end{array}$ & $\begin{array}{l}0,38 \mathrm{~b} \\
0,53 \mathrm{ab} \\
0,34 \mathrm{~b} \\
0,95 \mathrm{a}\end{array}$ & $\begin{array}{l}0,43 \mathrm{~b} \\
0,47 \mathrm{~b} \\
0,44 \mathrm{~b} \\
0,70 \mathrm{a}\end{array}$ & $\begin{array}{l}0,37 a \\
0,42 a \\
0,42 a \\
0,59 a\end{array}$ & $\begin{array}{l}0,43 a \\
0,42 a \\
0,44 a \\
0,53 a\end{array}$ & $\begin{array}{l}0,37 a \\
0,42 a \\
0,42 a \\
0,59 a\end{array}$ \\
\hline
\end{tabular}

(1) Testemunha sem calagem; 2) cal cário aplicado ao longo do perfil do sol o no sulco de plantio; 3) calcário aplicado na superfície sem incorporação; 4) cal cário aplicado ao longo do perfil do solo, no sulco de plantio, mais calcário na superfície, sem incorporação. As médias seguidas de uma mesma letra na coluna, considerando a mesma distância, profundidade e amostragem, não diferem significativamente entre si, pelo teste de Tukey a $5 \%$.

interação cultivares $x$ modalidades de aplicação de cal cário, e dessa forma, avaliou-se isoladamente o efeito de cultivares e de modalidades de aplicação de calcário.

Os teores médios de P, K, Ca, Mg, Cu, Fe, Mn eZn não diferiram entre os três cultivares testados (Quadro 6). Esse resultado está relacionado com os baixos teores de alumínio trocável no solo e com a fertilidade do sol o da área experimental (Quadro 1), os quais não influenciaram a absorção dos nutrientes anal isados, condições estas que contribuíram para o adequado status nutricional em todos os cultivares. É relevante ressaltar que os teores de todos os nutrientes analisados, em todos os cultivares, mantiveram-se dentro da faixa considerada adequada para plantas de milho (Büll, 1993).

De forma semelhante, não foram observadas diferenças estatísticas nos teores de nutrientes em razão da modalidade de aplicação de calcário (Quadro 7). A condição adequada de umidade e o nível defertilidade do solo, duranteo cido da cultura, podem ser as possíveis causas da não-diferenciação entre os tratamentos, impedindo que os cultivares testados exibissem distinção quanto à tolerância ao $\mathrm{Al}^{3+}$. A ausência de variações no status nutricional das culturas em resposta à calagem, em diferentes sistemas de cultivo, foi observada por Caires et al . (1988) e Moreira et al. (2001). No entanto, Caires et al. (2001), estudando a aplicação de cal cário e gesso em PD, verificaram que a calagem aumentou os teores de $\mathrm{Ca}$ e $\mathrm{Mg}$ e reduziu as concentrações de Zn e $\mathrm{Mn}$ nas fol has de soja, enquanto as doses de gesso aumentaram somente os teores foliares de Ca.

\section{Características agronômicas}

Analisando as características agronômicas, verificou-se que não houve efeito significativo para as modalidades de aplicação de calcário, a $5 \%$ de probabilidade, tampouco para a produtividade de grãos (Quadro 8). Resultados semelhantes foram obtidos por Pöttker \& Ben (1998), Caires et al . (1998, 2000) e Moreira et al. (2001), que verificaram quea calagem, em PD, não incrementou a produtividade das culturas testadas. U ma explicação para este resultado é que a calagem, mesmo atuando apenas na superfície, mantém teores suficientes deCa eMg 
Quadro 5. Valores médios de alumínio trocável nos diferentes tratamentos amostrados aos 30 e 150 dias da calagem, nas distâncias laterais a partir da linha de semeadura $(0,5,10,15$ e $25 \mathrm{~cm})$ e nas profundidades de 0-2,5, 2,5-5, 5-10, 10-15 e 15-20 cm

\begin{tabular}{|c|c|c|c|c|c|c|c|c|c|c|c|}
\hline \multirow{3}{*}{ Profundidade } & \multirow{3}{*}{ Tratamento(1) } & \multicolumn{10}{|c|}{ Distância lateral (cm) } \\
\hline & & \multicolumn{2}{|r|}{$\mathbf{0}$} & \multicolumn{2}{|c|}{5} & \multicolumn{2}{|c|}{10} & \multicolumn{2}{|c|}{15} & \multicolumn{2}{|c|}{25} \\
\hline & & 30 & 150 & 30 & 150 & 30 & 150 & 30 & 150 & 30 & 150 \\
\hline $\mathrm{cm}$ & & & & & & $\mathrm{cn}$ & $l_{c} \mathrm{dm}^{-3}$ & & & & \\
\hline $0-2,5$ & $\begin{array}{l}\text { Testemunha } \\
\text { Sulco } \\
\text { Superfície } \\
\text { Sulco + superf. }\end{array}$ & $\begin{array}{l}- \\
- \\
- \\
-\end{array}$ & $\begin{array}{l}0,22 \mathrm{a} \\
0,25 \mathrm{a} \\
0,06 \mathrm{~b} \\
0,08 \mathrm{~b}\end{array}$ & $\begin{array}{l}0,17 a b \\
0,26 a \\
0,11 b c \\
0,03 c\end{array}$ & $\begin{array}{l}0,27 a b \\
0,37 a \\
0,03 c \\
0,13 b c\end{array}$ & $\begin{array}{l}0,19 \mathrm{a} \\
0,18 \mathrm{a} \\
0,05 \mathrm{~b} \\
0,07 \mathrm{~b}\end{array}$ & $\begin{array}{l}0,26 a b \\
0,36 a \\
0,11 b \\
0,18 a b\end{array}$ & $\begin{array}{l}0,18 a b \\
0,23 a \\
0,06 c \\
0,09 b c\end{array}$ & $\begin{array}{l}0,28 \mathrm{a} \\
0,29 \mathrm{a} \\
0,12 \mathrm{~b} \\
0,10 \mathrm{~b}\end{array}$ & $\begin{array}{l}0,21 \mathrm{a} \\
0,22 \mathrm{a} \\
0,13 \mathrm{a} \\
0,11 \mathrm{a}\end{array}$ & $\begin{array}{l}0,22 a b \\
0,28 a \\
0,06 c \\
0,10 b c\end{array}$ \\
\hline $2,5-5$ & $\begin{array}{l}\text { Testemunha } \\
\text { Sulco } \\
\text { Superfície } \\
\text { Sulco + superf. }\end{array}$ & $\begin{array}{l}- \\
- \\
- \\
-\end{array}$ & $\begin{array}{l}0,32 \mathrm{a} \\
0,27 \mathrm{ab} \\
0,17 \mathrm{bc} \\
0,07 \mathrm{c}\end{array}$ & $\begin{array}{l}0,26 \mathrm{a} \\
0,30 \mathrm{a} \\
0,33 \mathrm{a} \\
0,11 \mathrm{~b}\end{array}$ & $\begin{array}{l}0,42 \mathrm{a} \\
0,37 \mathrm{a} \\
0,35 \mathrm{ab} \\
0,19 \mathrm{~b}\end{array}$ & $\begin{array}{l}0,31 \mathrm{a} \\
0,22 \mathrm{ab} \\
0,20 \mathrm{~b} \\
0,13 \mathrm{~b}\end{array}$ & $\begin{array}{l}0,45 a \\
0,40 a \\
0,37 a \\
0,22 a\end{array}$ & $\begin{array}{l}0,32 a \\
0,20 a b \\
0,28 a b \\
0,14 b\end{array}$ & $\begin{array}{l}0,42 a \\
0,37 a \\
0,42 a \\
0,21 a\end{array}$ & $\begin{array}{l}0,23 a \\
0,28 a \\
0,24 a \\
0,19 a\end{array}$ & $\begin{array}{l}0,35 \mathrm{a} \\
0,34 \mathrm{a} \\
0,27 \mathrm{ab} \\
0,14 \mathrm{~b}\end{array}$ \\
\hline $5-10$ & $\begin{array}{l}\text { Testemunha } \\
\text { Sulco } \\
\text { Superfície } \\
\text { Sulco + superf. }\end{array}$ & $\begin{array}{l}- \\
- \\
- \\
-\end{array}$ & $\begin{array}{l}0,41 \mathrm{a} \\
0,36 \mathrm{ab} \\
0,42 \mathrm{a} \\
0,18 \mathrm{~b}\end{array}$ & $\begin{array}{l}0,36 a b \\
0,33 a b \\
0,48 a \\
0,23 b\end{array}$ & $\begin{array}{l}0,51 \mathrm{a} \\
0,38 \mathrm{ab} \\
0,53 \mathrm{a} \\
0,18 \mathrm{~b}\end{array}$ & $\begin{array}{l}0,34 a \\
0,33 a \\
0,40 a \\
0,25 a\end{array}$ & $\begin{array}{l}0,48 \mathrm{a} \\
0,40 \mathrm{a} \\
0,48 \mathrm{a} \\
0,28 \mathrm{a}\end{array}$ & $\begin{array}{l}0,28 \mathrm{a} \\
0,33 \mathrm{a} \\
0,43 \mathrm{a} \\
0,24 \mathrm{a}\end{array}$ & $\begin{array}{l}0,48 a \\
0,41 a \\
0,58 a \\
0,33 a\end{array}$ & $\begin{array}{l}0,36 a b \\
0,31 a b \\
0,49 a \\
0,20 b\end{array}$ & $\begin{array}{l}0,46 a \\
0,47 a \\
0,49 a \\
0,31 a\end{array}$ \\
\hline $10-15$ & $\begin{array}{l}\text { Testemunha } \\
\text { Sulco } \\
\text { Superfície } \\
\text { Sulco + superf. }\end{array}$ & $\begin{array}{l}- \\
- \\
- \\
-\end{array}$ & $\begin{array}{l}0,39 a b \\
0,29 a b \\
0,55 a \\
0,23 b\end{array}$ & $\begin{array}{l}0,32 \mathrm{a} \\
0,35 \mathrm{a} \\
0,48 \mathrm{a} \\
0,23 \mathrm{a}\end{array}$ & $\begin{array}{l}0,45 a b \\
0,29 b c \\
0,60 a \\
0,11 c\end{array}$ & $\begin{array}{l}0,29 a \\
0,29 a \\
0,47 a \\
0,25 a\end{array}$ & $\begin{array}{l}0,46 \mathrm{a} \\
0,41 \mathrm{a} \\
0,51 \mathrm{a} \\
0,28 \mathrm{a}\end{array}$ & $\begin{array}{l}0,35 a b \\
0,24 \mathrm{~b} \\
0,46 \mathrm{a} \\
0,27 \mathrm{ab}\end{array}$ & $\begin{array}{l}0,43 a \\
0,42 a \\
0,62 a \\
0,36 a\end{array}$ & $\begin{array}{l}0,34 a \\
0,36 a \\
0,46 a \\
0,20 a\end{array}$ & $\begin{array}{l}0,44 a \\
0,32 a \\
0,49 a \\
0,43 a\end{array}$ \\
\hline $15-20$ & $\begin{array}{l}\text { Testemunha } \\
\text { Sulco } \\
\text { Superfície } \\
\text { Sulco + superf. }\end{array}$ & $\begin{array}{l}- \\
- \\
- \\
-\end{array}$ & $\begin{array}{l}0,36 \mathrm{ab} \\
0,30 \mathrm{ab} \\
0,54 \mathrm{a} \\
0,19 \mathrm{~b}\end{array}$ & $\begin{array}{l}0,28 a b \\
0,32 a b \\
0,43 a \\
0,21 b\end{array}$ & $\begin{array}{l}0,41 \mathrm{a} \\
0,35 \mathrm{ab} \\
0,47 \mathrm{a} \\
0,15 \mathrm{~b}\end{array}$ & $\begin{array}{l}0,28 a \\
0,33 a \\
0,38 a \\
0,24 a\end{array}$ & $\begin{array}{l}0,38 a \\
0,37 a \\
0,48 a \\
0,18 a\end{array}$ & $\begin{array}{l}0,31 a \\
0,33 a \\
0,38 a \\
0,20 a\end{array}$ & $\begin{array}{l}0,41 \mathrm{a} \\
0,39 \mathrm{a} \\
0,56 \mathrm{a} \\
0,27 \mathrm{a}\end{array}$ & $\begin{array}{l}0,29 a \\
0,38 a \\
0,37 a \\
0,29 a\end{array}$ & $\begin{array}{l}0,40 a \\
0,45 a \\
0,41 a \\
0,32 a\end{array}$ \\
\hline
\end{tabular}

(1) Testemunha sem calagem; 2) cal cário aplicado ao longo do perfil do sol o no sulco de plantio; 3) cal cário aplicado na superfície sem incorporação; 4) calcário aplicado ao longo do perfil do solo, no sulco de plantio, mais cal cário na superfície, sem incorporação. As médias seguidas de uma mesma letra na coluna, considerando a mesma distância, profundidade e amostragem, não diferem significativamente entre si, pelo teste de Tukey a $5 \%$.

no sol o e aumenta a absorção de nutrientes (Caires et al., 2001), mesmo não promovendo a correção do $\mathrm{Al}^{3+}$ em subsuperfície ou o crescimento de raízes em profundidade.

Quadro 6. Teores médi os de $\mathrm{P}, \mathrm{K}, \mathrm{Ca}$ e $\mathrm{Mg}$ (dag $\mathrm{gg}^{-1}$ ), $\mathrm{Cu}, \mathrm{Fe}, \mathrm{Mn}$ e $\mathrm{Zn}\left(\mathrm{mg} \mathrm{kg}^{-1}\right)$ na matéria seca de folhas, de três cultivares de milho (Z 8447 tolerante ao alumínio, AL 25 medianamente tolerante ao alumínio e AG 122 muito sensível ao alumínio)

\begin{tabular}{lrrr}
\hline \multirow{3}{*}{ Nutriente } & \multicolumn{3}{c}{ Cultivar } \\
\cline { 2 - 4 } & $\mathbf{Z} \mathbf{8 4 4 7}$ & AL 25 & AG 122 \\
\hline Fósforo & 0,28 & 0,27 & 0,26 \\
Potássio & 18,15 & 20,25 & 21,61 \\
Cálcio & 0,57 & 0,49 & 0,45 \\
Magnésio & 0,24 & 0,22 & 0,20 \\
Cobre & 14,88 & 12,55 & 11,72 \\
Ferro & 204,52 & 172,80 & 198,84 \\
Manganês & 145,23 & 151,07 & 108,28 \\
Zinco & 31,66 & 29,10 & 26,47 \\
\hline
\end{tabular}

A boa produtividade obtida pela testemunha (Quadro 8), como também observaram Caires et al. (1998) e Pöttker \& Ben (1998), pode ser atribuída à ausência de déficit hídrico no período do experimento e à fertilidade do solo, pois, de acordo com Caires et al. (1998), é possível obter el evada produção, mesmo em solo com pH relativamente baixo, desde que os teores de cálcio, magnésio e potássio sejam adequados.

Além da fertilidade do solo, da baixa saturação de alumínio (Quadro 1) e da ausência de déficit hídrico no presente experimento, outra possível explicação para os resultados obtidos éa capacidade queas plantas têm de desenvolver em pequena faixa de sol o corrigida (Pöttker \& Ben, 1998; Caires et al., 2001). Deacordo com Scott et al. (1997), a expl oração da subsuperfície em solos ácidos pode não ser necessária quando há nutrientes eágua disponíveis na superfície do solo. Resultados semel hantes foram observados por Rodrigues (1997), aplicando cal cário apenas no anel superior de col unas de solo, em duas variedades de café, uma sensível eoutra toleranteà toxidez de alumínio. 
Quadro 7. Teores médios de $\mathrm{P}, \mathrm{K}$, Ca e Mg e Cu, Fe, Mn e Zn na matéria seca de folhas de milho, nas diferentes modalidades de calagem estudadas

\begin{tabular}{|c|c|c|c|c|}
\hline \multirow{2}{*}{ Nutriente } & \multicolumn{4}{|c|}{ Modalidade $^{(1)}$} \\
\hline & Testemunha & Sulco & Superfície & Sulco + superfície \\
\hline Fósforo (dag kg-1) & 0,27 & 0,26 & 0,27 & 0,27 \\
\hline Potássio (dag kg-1) & 2,03 & 2,01 & 2,00 & 1,95 \\
\hline Cálcio (dag kg-1) & 0,53 & 0,47 & 0,50 & 0,52 \\
\hline Magnésio (dag kg-1) & 0,22 & 0,19 & 0,21 & 0,23 \\
\hline Cobre $\left(\mathrm{mg} \mathrm{kg}^{-1}\right)$ & 13,86 & 12,57 & 13,05 & 12,71 \\
\hline Ferro $\left(\mathrm{mg} \mathrm{kg}^{-1}\right)$ & 194,21 & 185,85 & 194,60 & 190,88 \\
\hline Manganês $\left(\mathrm{mg} \mathrm{kg}^{-1}\right)$ & 145,49 & 129,88 & 159,46 & 104,62 \\
\hline Zinco (mg kg-1) & 27,62 & 30,08 & 30,67 & 27,93 \\
\hline
\end{tabular}

Não houve diferença significativa pelo teste $\mathrm{F}$ a $5 \%$.

(1) Testemunha sem calagem; calcário aplicado ao longo do perfil do solo no sulco de plantio; calcário aplicado na superfície sem incorporação; e calcário aplicado ao longo do perfil do solo, no sulco de plantio, mais cal cário na superfície, sem incorporação.

Quadro 8. Valores médios de altura de plantas (AP), altura da espiga superior (AE), estande final (EF), número de espigas por hectare (NE) e produtividade de grãos (PG) e peso de espigas (PE) de milho nas diferentes modalidades de calagem estudadas

\begin{tabular}{|c|c|c|c|c|c|c|}
\hline Modalidade $e^{(1)}$ & AP & AE & EF & NE & PG & PE \\
\hline & 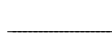 & - & pl ha-1 & esp ha-1 & \multicolumn{2}{|c|}{ - $\mathrm{kg} \mathrm{ha}^{-1}$} \\
\hline Testemunha & 230,78 & 121,89 & $62.473,55$ & $63.214,33$ & $8.998,22$ & $11.129,00$ \\
\hline Sulco & 233,44 & 125,67 & $58.074,11$ & $57.407,45$ & $7.936,89$ & $9.540,11$ \\
\hline Superfície & 230,22 & 119,89 & $62.354,45$ & $62.381,00$ & $7.663,56$ & $9.558,67$ \\
\hline Sulco + superfície & 238,89 & 128,33 & $59.185,11$ & $61.277,78$ & $7.996,00$ & $9.642,78$ \\
\hline
\end{tabular}

Não houve diferença significativa pelo teste F a $5 \%$.

(1) Testemunha sem calagem; calcário aplicado ao longo do perfil do solo no sulco de plantio; calcário aplicado na superfície sem incorporação, e calcário aplicado ao longo do perfil do solo, no sulco de plantio, mais calcário na superfície, sem incorporação.

\section{CONCLUSÕES}

1. A aplicação de cal cário apenas na superfície teve efeito restrito até à profundidade de $5 \mathrm{~cm}$, na qual manteve valores mais altos de $\mathrm{pH}$ e mais baixos de $\mathrm{Al}^{3+}$.

2. A aplicação de calcário ao longo do perfil do solo no sulco de semeadura mais a aplicação de cal cário na superfície do sol o foi a alternativa mais eficiente para correção do $\mathrm{pH}$, elevação de $\mathrm{Ca}^{2+} \mathrm{e}$ $\mathrm{Mg}^{2+}$ e redução de $\mathrm{Al}^{3+}$ do solo.

3. Não houve efeito das modalidades de aplicação de calcário no estado nutricional dos cultivares testados nem sobre as características agronômicas da cultura do milho analisadas.

\section{LITE RATURA CITADA}

ANDERSON, D.L. \& HENDRICK, J.G. Subsoil lime injector. Soil Sci. Soc. Am. J ., 47:337-339, 1983.
ASSOCIATION OF OFFICIAL ANALYTICAL CHEMISTSAOAC. Official methods of analysis. 12 ed. Washington, 1975. 1094p.

BAYER, C. \& MIELNICZUK, J. Características químicas do solo afetadas por métodos de preparo e sistemas de cultura. R. Bras. Ci. Solo, 21:105-112, 1997.

BRAGA,J .M. \& DEFELIPO, B.V. Determinação espectrofotomé trica de fósforo em extrator de solo e material vegetal. R. Ceres, 21:73-85, 1974.

BÜLL, L.T. Nutrição mineral do milho. In: BÜLL, L.T. \& CANTARELLA, H., eds. Cultura do milho: fatores que afetam a produtividade. Piracicaba, POTAFOS, 1993. p.63145.

CAIRES, E.F.; WEIRICH NETO, P.H.; J USTINO, A. \& DIAS, J. Eficiência de métodos de incorporação de calcário na correção da acidez do solo e resposta do mil ho cultivado em campo nativo. In: CONGRESSO BRASILEIRO DE CIÊNCIA DO SOLO, 26., Rio de J aneiro, 1997. Resumos. Viçosa, MG, Universidade Federal de Viçosa, Sociedade Brasileira de Ciência do Solo, 1997. CD-ROM 
CAIRES, E.F.; CHUEIRI, W.A.; MADRUGA, E.F. \& FIGUEIREDO, A. Alterações de características químicas do solo e resposta da soja ao cal cário e gesso aplicados na superfície em sistema de cultivo sem preparo do solo. R. Bras. Ci. Solo, 22:27-34, 1998

CAIRES, E.F.; FONSECA, A.F.; MENDES, J .; CHUEIRI, W.A. \& MADRUGA, E.F. Produção de milho, trigo, e soja em função das alterações das características químicas do solo pela aplicação de calcário e gesso na superfície, em sistema de plantio direto. R. Bras. Ci. Solo, 23:315-327, 1999.

CAIRES, E.F.; BANZATTO, D.A. \& FONSECA, A.F. Calagem na superfície em sistema plantio direto. R. Bras. Ci. Solo, 24:161-169, 2000.

CAIRES, E.F.; BANZATTO, D.A.\& FONSECA, A.F. Crescimento radicular e nutrição da soja cultivada no sistema plantio direto em resposta ao cal cário e gesso na superfície. R. Bras. Ci. Solo, 25:1029-1040, 2001.

CAMARGO, A.P.; van RAIJ , B.; CANTARELLA, H.; ROCHA, T.R.; NAGAI, V. \& MASCARENHAS, H.A.A. Efeito da calagem nas produções de cinco cultivos de milho, seguidos de algodão e soja. Pesq. Agropec. Bras., 17:1007-1012, 1982.

DEFELIPO, B.V. \& RIBEIRO, A.C. Análise química do solo. Viçosa, MG, Universidade Federal de Viçosa, 1981. 17p. (Boletim de Extensão, 29)

ERNANI, P.R.; NASCIMENTO, J.A.L. \& OLIVEIRA, L.C. Increase of grain and green matter of corn by liming. R. Bras. Ci. Solo, 22:275-280, 1998.

ERNANI, P.R., BAYER, C. \& MAESTRI, L. Corn yield as affected by liming and tillage system on an acid Brazilian Oxisol. Agron. J., 94:305-309, 2002.

FURLANI, P.R. Tolerância de cultivares de milho ao alumínio. In: SEMINÁRIO SOBRE A CULTURA DO MILHO "SAFRINHA", 3., Assis, 1995. Resumos. Assis, Instituto Agronômico de Campinas, 1995. p.71-75.

HARGROVE, W.L.; REID, J.T.;TOUCHTON, J.T. \& GALLAHER, R.N. Influence of tillage practices on the fertility status of an acid soil double-cropped to wheat and soybeans. Agron. J ., 74:684-687, 1982.

KAUFFMAN, M.D. \& GARDNER, E.H. Segmental liming of soil and its effect on the growth of wheat. Agron. J., 70:331-6, 1978.

MALAVOLTA, E.; VITTI, G.C. \& OLIVEIRA, S.A. Avaliação do estado nutricional das plantas: princípios e aplicações. Piracicaba, POTAFOS, 1989. 201p.

MIYAZAWA, M.; PAVAN, M.A. \& SANTOS, J.C.R. Effect of addition of crop residues on the leaching of $\mathrm{Ca}$ and $\mathrm{Mg}$ in Oxisols. In: INTERNATIONAL SYMPOSIUM ON PLANTSOIL INTERACTIONS AT LOW pH, 4., Belo Horizonte, 1996. Abstracts. Belo Horizonte, Sociedade Brasileira de Ciência do Solo/Empresa Brasileira de Pesquisa Agropecuária-CPAC, 1996. p.8.

MOREIRA, S.G.; KIEHL, J.C.; PROCHNOW, L.I \& PAULETTI, V. Calagem em sistema de semeadura direta e efeitos sobre a acidez, do solo, disponibilidade de nutrientes e produtividade de milho e soja. R. Bras. Ci. Solo, 25:71-81, 2001.
OLIVEIRA, E.L. \& PAVAN, M.A. Redução da acidez do solo pelo uso de calcário e gesso e resposta da soja cultivada em plantio direto. In: REUNIÃO BRASILEIRA DE FERTILIDADE DO SOLO E NUTRIÇÃO DE PLANTAS, 21., Petrolina, 1994. Anais. Petrolina, Sociedade Brasileira de Ciência do Solo/Empresa Brasileira de Pesquisa Agropecuária-CPATSA, 1994. p.178.

PAIVA, P.J .R.; VALE, F.R.; FURTINI NETO, A.E. \& FAQUIN, V. Acidificação de um Latossolo Roxo do estado do Paraná sob diferentes sistemas de manejo. R. Bras. Ci. Solo, 20:7175, 1996.

PETRERE, C.\& ANGHINONI, I. Alteração deatributos químicos no perfil do solo pela calagem superficial em campo nativo. R. Bras. Ci. Solo, 25:885-895, 2001.

PÖTTKER, D.; DERNARDIN, J .E.; BEN, J.R. \& KOCHHANN, R.A. Efeito da aplicação de cal cário sobre pastagem natural no rendimento de grãos de soja e de trigo cultivados no sistema plantio direto. In: CONGRESSO BRASI LEIRO DE CIÊNCIA DO SOLO, 25., Viçosa, 1995. Anais. Viçosa, MG, Universidade Federal de Viçosa/Sociedade Brasileira de Ciência do Solo, 1995. p.1111-1113.

PÖTTKER, D. \& BEN,J .R. Calagem para uma rotação deculturas nosistema plantio direto. R. Bras. Ci. Solo, 22:675-684, 1998.

RODRIGUES, L.A. Crescimento e composição mineral na parte aérea e nas raízes de duas variedades de café em resposta à calagem na subsuperfície do solo. Viçosa, MG, Universidade Federal de Viçosa, 1997. 89p. (Tese de Mestrado)

SÁ, J.C.M. Plantio direto: a alternativa de manejo do solo em regiões tropicais. In: FT-PESQUISA E SEMENTES. Recomendações de cultivo 1995. Ponta Grossa, 1995. p.5-14.

SANTOS, H.P.; TOMM, G.O. \& LHAMBY, J.C.B. Plantio direto versus convencional: efeito na fertilidade do solo e no rendimento de grãos de culturas em rotação com cevada. R. Bras. Ci. Solo, 19:449-454, 1995.

SANTOS, H.P. \& SIQUEIRA, O.J.W. Plantio direto e rotação de culturas para cevada: efeitos sobre a fertilidade do solo. R. Bras. Ci. Solo, 20:163-169, 1996.

SCHAEFER, C.E.G.R.; SOUZA, C.M.; VALLEJ OS M., F.S.; VIANA, J.H.M.; GALVÃO, J. C.C. \& RIBEIRO, L.M. Características da porosidade de um argissolo vermelhoamarel o submetido a diferentes sistemas de preparo de solo. R. Bras. Ci. Solo, 25:765-769, 2001.

SCOTT, B.J .; CONYERS, M.K.; POILE, G.J . \& CULLIS, B.R. Subsurface acidity and liming affect yield of cereals. Aust. J. Agric. Res., 48:843-854, 1997.

SILVA, J B.C.; NOVAIS, R.F. \& SEDIYAMA, C.S. I dentificação de genótipos de sorgo tolerantes à toxicidade de alumínio. R. Bras. Ci. Solo, 7:77-83, 1984a.

SI LVA, J .B.C.; NOVAIS, R.F. \& SEDIYAMA, C.S. Comportamento de genótipos de soja com alta saturação de alumínio. Pesq. Agropec. Bras., 19:287-298, 1984b.

WOLF, J.M. Soil water relation in oxisols of Puerto Rico and Brazil. In: BORNEMISZA, E. \& ALVARADO, A., eds. Soil management in Tropical America. Raleigh, N orth Carolina State University, 1975. p.145-154. 